\title{
Exposição Humana à Radiação Eletromagnética Não Ionizante e o Princípio da Precaução: Ênfase na Telefonia Celular
}

\author{
José Braga Neto e Francisco J. Alves de Aquino
}

\begin{abstract}
Resumo-Neste artigo realizamos uma pesquisa exploratória com o objetivo de colher informações sobre os níveis de exposição humana à radiação eletromagnética emitidas pelos celulares e suas antenas. Em seguida, estudamos as hipóteses relacionadas aos prejuízos causados pela poluição eletromagnética sobre a saúde humana e apresentamos a fundamentação para a correta aplicação do Princípio da Precaução.
\end{abstract}

Palavras-Chave-Telefonia celular, radiação não ionizante, princípio da precaução.

Abstract-In this paper we performed a survey aimed at collecting information on levels of human exposure to electromagnetic radiation emitted by mobile phones and their antennas. Then, we studied the hypotheses related to the damage caused by electromagnetic pollution on human health and we present the rationale for the correct application of the precautionary principle.

Keywords-Mobile phone, non-ionizing radiation, precautionary principle.

\section{INTRODUÇÃO}

Nos últimos anos, com o intenso desenvolvimento da microeletrônica e das comunicações, houve um aumento significativo dos campos eletromagnéticos presentes nos ambientes residenciais, comerciais e industriais. O uso dos aparelhos celulares pode vir a desencadear sérios problemas ambientais, principalmente em grandes centros urbanos onde as pessoas consomem intensamente produtos tecnológicos.

Com a explosão da telefonia celular, como mostra a Fig. 1 , centenas de antenas foram instaladas nas cidades, sendo que algumas estão instaladas sobre prédios e outra muito próximas às áreas residenciais. Dados oficiais indicam que nos primeiros meses de 2008 existiam mais de 3,96 bilhões de terminais móveis em utilização em todo o mundo e mais que 122 milhões no Brasil, em 2007 [1]. Em paralelo com o vertiginoso crescimento da utilização dos sistemas móveis por uma parcela significativa da população, tem crescido também a preocupação com os riscos à saúde que a radiação emitida por esta tecnologia pode representar. Segundo a teoria eletromagnética [2], radiação é o resultado da aceleração de partículas carregadas. Dependendo do comprimento de onda e frequência, existem vários nomes diferentes para a radiação eletromagnética, como mostrado na Fig. 2.

As radiações são classificadas segundo a quantidade de energia transportada, ou seja, para àquelas que carregam

José Braga Neto e Francisco J. A. de Aquino, Departamento de Telemática, Instituto Federal de Educação, Ciência e Tecnologia do Ceará, Fortaleza, Brasil, E-mails: jbneto.mb@gmail.com,fcoalves_aq@ifce.edu.br.

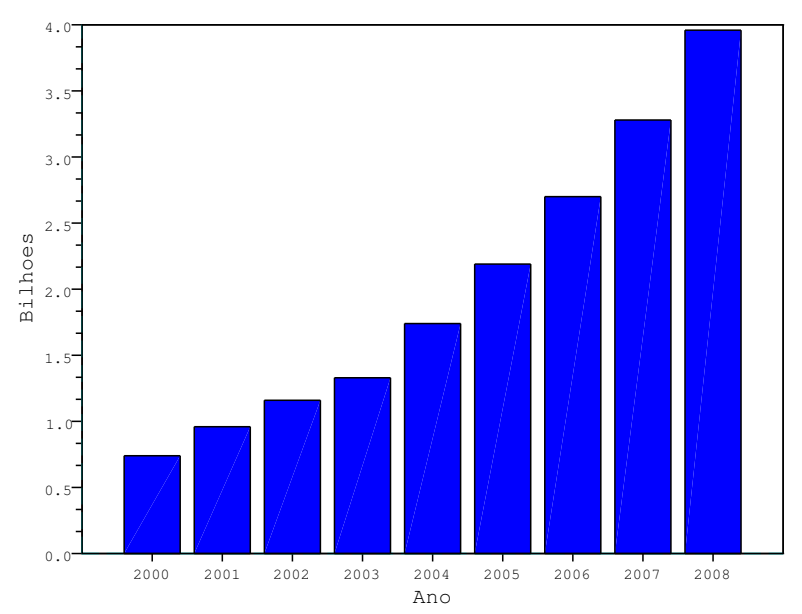

Fig. 1. Evolução no número de telefones celulares no mundo

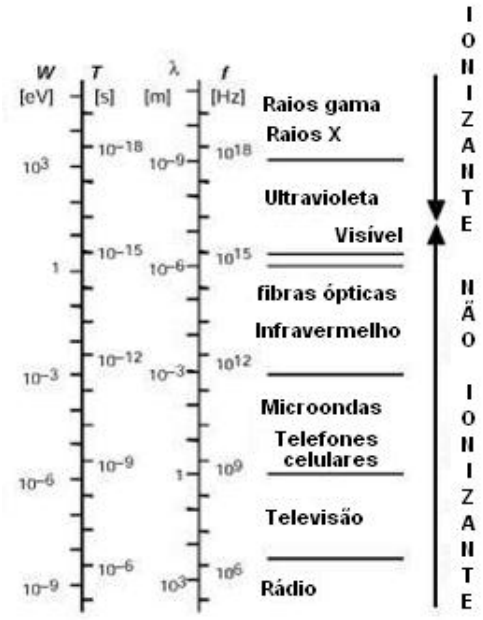

Fig. 2. Espectro Eletromagnético, segundo o comprimento de onda e frequência

altos níveis de energia damos o nome de radiação ionizante, enquanto que as radiações não ionizantes transportam baixos níveis de energia. A exposição humana a essas radiações produz dois principais efeitos: o térmico e o não-térmico. A profundidade com que a radiação penetra em um material ou tecido vivo pode ser calculada por [2]:

$$
\delta=\left(\frac{\rho}{\pi f \mu}\right)^{1 / 2}
$$

onde $\rho$ é a resistividade $(\Omega . m), \mu$ é a permeabilidade 
magnética do tecido e $f$ a frequência da onda incidente.

Atualmente, existem algumas diretrizes [3, 4, 5, 6] que determinam os limites básicos de exposição às radiações eletromagnéticas a fim de proteger a população dos seus efeitos nocivos, e todas essas diretrizes utilizam a Taxa de Absorção Específica (SAR) como grandeza de maior interesse. $\mathrm{O}$ fator SAR representa a taxa de potência absorvida por unidade de massa $(W / K g)$, e é dado por [2]:

$$
S A R=\frac{P_{a b s}}{\rho}=\frac{\pi \varepsilon_{0} f \varepsilon_{r}^{\prime \prime}}{\rho}\|E\|^{2},
$$

onde $\varepsilon_{0}$ é a permissividade no vácuo e $E$ é o campo elétrico.

Entretanto, tais diretrizes não levam em consideração os resultados a médio e longo prazo e tampouco os efeitos nãotérmicos.

\section{Aspectos Biológicos}

Todos os organismos vivos são sensíveis à energia eletromagnética, ou seja, uma alteração ocasionada por uma radiação artificial pode produzir mudanças biológicas consideráveis. Estudos recentes concluíram que bastam apenas 45 minutos de exposição a uma radiação eletromagnética de $0,7 \mathrm{~V} / \mathrm{m}$ emitida por um aparelho celular para se observar efeitos nocivos à saúde [7]. Atualmente, há diversos estudos conclusivos acerca dos efeitos térmicos da radiação em nosso organismo, tais estudos apontam para a possibilidade do surgimento de patologias associadas ao aumento da temperatura corporal, assim como alertou a OMS para o aparecimento de cataratas e glaucomas. No entanto, os resultados ainda são polêmicos quando tratamos dos efeitos não-térmicos, podemos encontrar alguns desses efeitos descritos na literatura atual, como alterações no sistema nervoso, cardiovascular e imunológico, bem como no metabolismo e em fatores hereditários [8]. Há também relatos de severa diminuição de produção de leite, emaciação, abortos espontâneos e natimortos em experimentos feitos com gado mantido próximo de uma ERB (Estação Rádio-Base) [9]. Diante disto, percebe-se que até mesmo a comunidade científica desconhece os males que podem ser causados pela utilização da telefonia móvel em longo prazo.

\section{PRINCÍPIO DA PRECAUÇÃO}

O direito ambiental surgiu com a finalidade de deter o poder destrutivo do capitalismo. A reivindicação de um Estado de Direito Ambiental que, há tempos, era motivo para risos dos estudiosos da época, hoje em dia já é uma realidade nos países de primeiro mundo e vem se tornando uma necessidade em países como o Brasil. A primeira manifestação do princípio da precaução se deu na Alemanha, no início na década de 70. Um pouco mais tarde foi introduzido na Europa e depois se expandiu por inúmeras convenções e conferências. No Brasil este princípio está presente desde a ECO-92 ou Rio-92, que resultou em uma das mais importantes expressões deste princípio, a Declaração do Rio da Conferência das Nações Unidas sobre o Meio Ambiente e Desenvolvimento, também conhecida como Agenda 21.
O grande crescimento da tecnologia móvel justifica o emprego do princípio da precaução não só no que diz respeito à saúde pública, mas também no campo patrimonial onde há desvalorização na ordem de até $40 \%$ de imóveis localizados nos arredores de fontes de radiação. O princípio da precaução deve ser aplicado quando a informação científica é insuficiente e, quando há indicações sobre possíveis efeitos nocivos no ambiente ou nos seres vivos, ou seja, cenários onde se exige a tomada de medidas preventivas, mesmo se alguma relação de causa e efeito não for completa e cientificamente estabelecida. O princípio da precaução é uma nova maneira de pensar, principalmente sobre a permanência da exposição a situações e agentes de risco em longo prazo. Ele nos desafia a fazer mudanças basilares no modo como permitimos e restringimos riscos. Vê-se, portanto, que a precaução é mais perfeita e completa do que a análise de riscos, pois expõe a incerteza dos resultados e considera as limitações do conhecimento científico.

\section{CONCLUSÕES}

Podemos afirmar que neste artigo apresentamos a fundamentação para a correta aplicação do Princípio da Precaução diante das incertezas científicas sobre os possíveis riscos da exposição à RNI. O conhecimento científico possui limitações, principalmente, em se tratando de estudos em médio e longo prazo. E, como para uma ciência exata só devese admitir resultados concretos, neste caso específico se deve pedir uma contribuição de uma importante disciplina interpretativa: o Direito. Este estudo busca uma maior integração entre a ciência tecnológica e o direito, principalmente em se tratando de riscos ao meio ambiente, a fim de resguardar os interesses da população como um todo, buscando, desta forma, um meio ambiente ecologicamente equilibrado.

\section{AGRADECIMENTOS}

Aos professores Fernando P. Garcia e Janaina C. Vasconcelos pela revisão de uma versão anterior deste material.

\section{REFERÊNCIAS}

[1] ANATEL, http://www.anatel.gov.br (Acesso: 27 de fevereiro de 2009).

[2] MOSELY, H. - "Non-Ionizing Radiation"Medical Physics Handbook 18, Adam Hilger, 1988.

[3] ICNRP - International Commission on Non-Ionizing Radiation Protection: Guidelines for limiting exposure to time-varying electric and electromagnetic fields. Health Physics vol. 74, April 1998.

[4] NRPB - National Radiological Protection Board: Mobile Phone Base Station (1999) http://www.hpa.org.uk (Acesso: 11 de março de 2009).

[5] IEEE C95.1-1991, Standard for Safety Levels with Respect to Human Exposure to Radio Frequency Electromagnetic Fields, $3 \mathrm{kHz}$ to $300 \mathrm{GHz}$, USA, 1992.

[6] IRPA Guidelines "Guidelines on Limits of Exposure to 50/60 Hz Electric and Magnetic Fields."Health Physics, vol. 58, No ${ }^{\circ} 1,1990$.

[7] BOVET - 2005 apud RIBEIRO e PESSOA "Os efeitos da Radiação Eletromagnética na Vida do Ser Humano: Uma Análise do Paradigma Ambiental, 2007".

[8] SAlleS, A. A. "Riscos à Saúde Provocados pelos Telefones Celulares"EGATEA, Revista da Escola de Engenharia UFRGS, vol. 24, No 1 (1997).

[9] MARCHESAN, Ana Maria Moreira "As Estações Rádio-Base de Telefonia Celular no Contexto de uma Sociedade de Risco". Revista de Direito Ambiental - 39. p. 34. 